\title{
Concerns about methods for determination of estrogens in body fluids
}

\author{
Robert T. Chatterton • Miguel Muzzio • \\ Peter H. Gann
}

Received: 3 October 2014 / Accepted: 22 October 2014/Published online: 11 November 2014

(C) Springer Science+Business Media New York 2014

To the Editor,

We have some concerns about the results presented in a paper by Loud et al. [1]. Although specimens from the 30 subjects in their study without BRCA1/2 mutations could not be measured by their method, subjects with these mutations had an unconjugated estradiol (E2) serum versus nipple aspirate fluid (NAF) concentration correlation of 0.77 and a corresponding correlation of 0.56 for E2 between serum and ductal lavage supernatant (DLS). Our concern is about their ability to measure any of the estrogens based on the method as described in the paper. The authors state in their earlier methods paper by Xu et al. [2], that the limit of quantitation of their method is $400 \mathrm{fg}$ (1.3-1.5 fmol). These are on-column values comparable to those that we have found [3]. Loud et al. [1] also report a limit of detection of $10 \mathrm{fg}$ on column using a capillary HPLC, which is not unreasonable. In the Methods section of the paper, they state that they collected up to $10 \mu \mathrm{l}$ of $\mathrm{NAF}$, diluted it to $1.0 \mathrm{ml}$, and split the samples into two aliquots of $0.4 \mathrm{ml}$ each for total and unconjugated estrogens. Each of these was processed, derivatized, and

This letter to the editor refers to the article available at doi:10.1007/ s10549-013-2821-6, and a rebuttal letter to this letter to the editor is available at doi:10.1007/s10549-014-3186-1.

\section{R. T. Chatterton $(\bowtie)$}

Northwestern University Feinberg School of Medicine, Chicago,

IL, USA

e-mail: chat@northwestern.edu

M. Muzzio

IIT Research Institute, Chicago, IL, USA

P. H. Gann

University of Illinois College of Medicine, Chicago, IL, USA reconstituted to $64 \mu \mathrm{l}$. One-eighth (equivalent to $8 \mu \mathrm{l}$ ) of the samples were injected into the HPLC. Thus, only $0.5 \mu \mathrm{l}$ of the initial NAF sample was injected. With the reported geometric mean concentration of unconjugated estradiol at $4.21 \mathrm{pmol} / \mathrm{l}(0.00421 \mathrm{fmol} / \mu \mathrm{l})$ (Table 3), the injected $0.5 \mu \mathrm{l}$ contained only $0.0021 \mathrm{fmol}$ or $0.6 \mathrm{fg}$ (using MW of $\sim 280$ ). Thus, they appear to be measuring $6 \%$ of the LOD on average. It is not possible to quantify such data reliably.

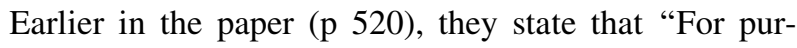
poses of this study, all BRCA1 or BRCA2 mutation positive postmenopausal women with sufficient volumes of serum, NAF and/or DLS specimens $(\geq 0.5 \mathrm{ml})$ were eligible for inclusion." If this was the actual volume of NAF extracted, this would bring the average mass of estradiol injected to $29.4 \mathrm{fg}$, well within the range of the assay, although values less than $34 \%$ of the mean would still be below the LOD. If this was the volume of NAF obtained, more information is needed to describe subjects that produced this volume of NAF, which in our experience is a very large yield. The data on DLS are also a problem. The stated concentrations are in the same range as the NAF values, but there is a question as to how the volume of breast fluid in the lavage was determined.

\section{References}

1. Loud JT, Gierach GL, Veenstra TD et al (2014) Circulating estrogens and estrogens within the breast among postmenopausal BRCA1/2 mutation carriers. Breast Cancer Res Treat 143:517-529

2. Xu X, Roman JM, Issaq HJ, Keefer LK, Veenstra TD, Ziegler RG (2007) Quantitative measurement of endogenous estrogens and estrogen metabolites in human serum by liquid chromatographytandem mass spectrometry. Anal Chem 79:7813-7821

3. Chatterton RT, Muzzio M, Heinz R, Gann PH, Khan SA (2014) Methodological considerations in estrogen assays of breast fluid and breast tissue. Steroids. doi:10.1016/j.steroids.2014.08.002 